\title{
Correção estática residual aplicada no processamento sísmico da linha 59-RL- 44 da Bacia do Parnaíba
}

\author{
Juliana A. G. Souza*, CPGG/UFBA, Milton J. Porsani e Wilker E. Souza INCT-GP/CNPq/Brasil \& CPGG/IGEO/UFBA
}

Copyright 2016, SBGf - Sociedade Brasileira de Geofísica.

Este texto foi preparado para a apresentação no VII Simpósio Brasileiro de Geofísica, Ouro Preto, 25 a 27 de outubro de 2016. Seu conteúdo foi revisado pelo Comitê Técnico do VII SimBGf, mas não necessariamente representa a opinião da SBGf ou de seus associados. É proibida a reprodução total ou parcial deste material para propósitos comerciais sem prévia autorização da SBGf.

\section{Abstract}

The residual static correction combined with the application of filtering methods, deconvolution, spectral balance, is of utmost importance for advanced seismic processing, improving the correlation between reflections on CMP gathers. This correction associated with the improvement of the signal to noise ratio provides more reliability to the results and continuity of the reflectors and to the imaging of the structures.

\section{Introdução}

Este trabalho apresenta o fluxograma usado no processamento da linha sísmica $59-R L-44$ da Bacia do Parnaíba e faz parte do acervo público da Agência Nacional do Petróleo (ANP). Os dados foram cedidos pela BP Energy do Brasil (BP) no ano de 2015 para pesquisas de natureza acadêmica através do projeto PABIP.

A sísmica de reflexão é um ramo da geofísica que pode ser dividida em três grandes áreas: a aquisição dos dados, o processamento e a interpretação dos resultados obtidos. Em todos os segmentos o objetivo é a interpretação mais fidedigna da subsuperfície. Para isso, desde o arranjo da aquisição até a escolha dos atributos, utilizados para interpretar uma linha sísmica, precisam ser escolhidos minuciosamente de acordo com o objeto investigado.

\section{Parâmetros de aquisição e processamento}

A linha sísmica processada contém 751 tiros e foi adquirida com 96 canais espaçados de 40 metros num arranjo split-spread simétrico e intervalo entre tiros de $80 \mathrm{~m}$ com cobertura CMP $2400 \%$. O intervalo de amostragem de cada registro é constante de $4 \mathrm{~ms}$, com um tempo de registro de $4 \mathrm{~s}$. O software utilizado para esse processamento foi o SeisSpace desenvolvido pela Landmark Graphics Corporation. O processamento sísmico foi desmembrado em duas fases: Na primeira, correspondente ao pré-processamento, tratamos do dado corrigindo efeitos que prejudicariam a qualidade do resultado final. Dentre as etapas pertencentes a esta, ganha destaque a correção estática, filtragens e deconvolução. A segunda fase, o processamento avançado, compreende etapas mais complexas que exigem do processador maior conhecimento e atenção: análise de velocidade, correção NMO e migração.

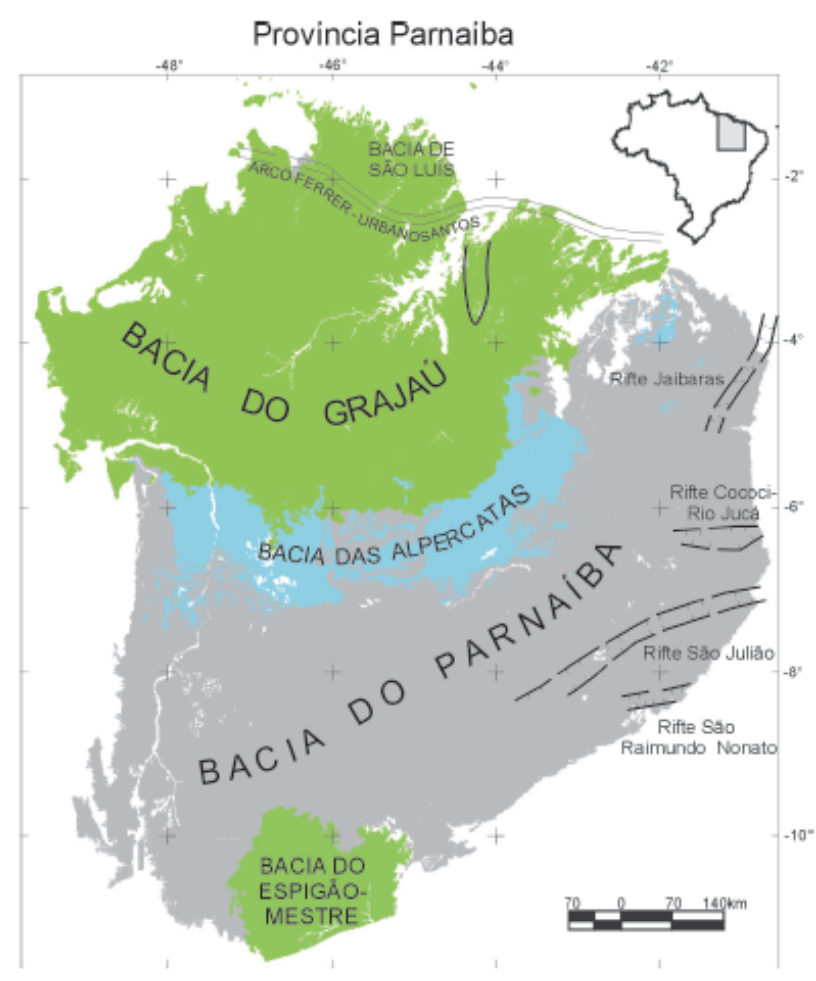

Figura 1: Localização da Bacia do Parnaíba. CPRM 2003

\section{Pré-processamento}

Antes de começar a organizar os dados em família CMP, common shot ou outra forma de visualização, é necessário que se faça a geometria do dado, cujo objetivo é assinalar em cada traço sísmico as coordenadas de ponto de tiro, receptor, ponto médio comum e seu offset correspondente (Silva, 2004).

\section{Correções estáticas}

Para corrigir os efeitos referentes à elevação da topografia e à zona intemperizada, mais conhecida como zona de baixa velocidade (ZBV) que causam deslocamento nos tempos de chegada das reflexões, precisa-se fazer a correção estática do dado que corresponde a um deslocamento fixo no tempo em cada traço sísmico. Depois de executada essa etapa, os traços sísmicos resultam como se todas as fontes e receptores estivessem posicionados sobre uma superfície plana, em um mesmo datum. Algumas informações são necessárias para se fazer a correção estática, são elas: elevação dos pontos de tiro e dos receptores e as velocidades da ZBV e da 
subZBV nesses pontos. As informações de elevação estão contidas em um relatório junto às coordenadas dos canais utilizados, porém a velocidade da subZBV será estimada através de picks feitos na primeira quebra do dado, ou seja, na primeira chegada de energia registrada pelos receptores (Figura 2). Após a obtenção dessas informações, é feito o cálculo das correções estáticas e por fim, a aplicação dela. Na Figura 3 podemos observar o resultado do uso da correção estática do tiro 201.

\section{Edição}

Muitas vezes faz-se necessária a eliminação total ou parcial dos traços com baixíssima razão sinal/ruído devido a problemas nos geofones, contaminação por ruídos transientes ou aleatórios, ou seja, traços que afetariam a qualidade do dado final. A função mute é obtida a partir de pontos selecionados diretamente no sismograma em que a amplitude fora desse limite é zerada e o módulo kill elimina completamente o traço zerando a amplitude ao longo dele. A essas operações, dá-se o nome de edição.

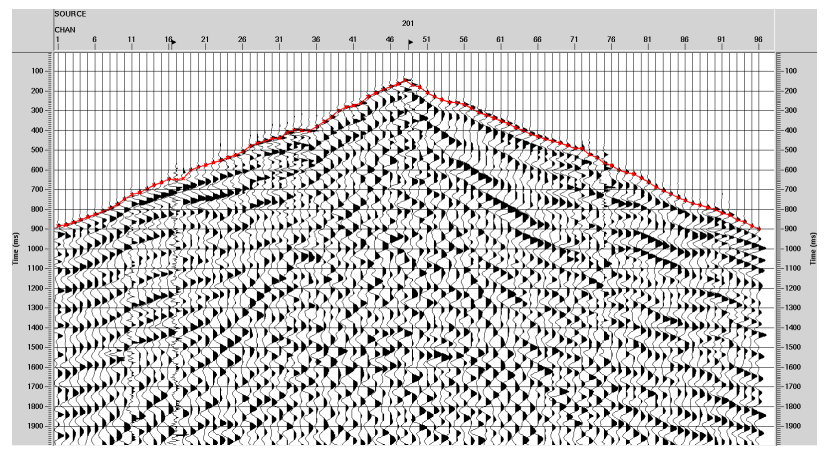

Figura 2: Picks de primeira quebra do tiro 201

\section{Deconvolução spike com consistência superficial}

O traço sísmico é comumente representado pelo modelo convolucional, em que este é o resultado da convolução de impulso gerado por uma fonte, composto pela resposta impulsiva da terra e uma série de ruídos. Assim, o modelo convolucional do traço sísmico é representado matematicamente por:

$$
S(t)=p(t) * r(t)+n(t)
$$

Onde $S(t)$ é o traço sísmico; $p(t)$ é o pulso sísmico gerado; $r(t)$ é a função refletividade e $n(t)$ é o ruído aleatório e * representa o operador de convolução. Com o aumento da profundidade dos refletores, o sinal sísmico perde resolução devido à dispersão da energia. Melhorar essa resolução temporalmente é de extrema importância para a exploração de alvos profundos e definição de espessura de camadas delgadas. A deconvolução ou filtragem inversa tem como objetivo a recuperação da resposta impulsiva terrestre a partir do sismograma. O método clássico de filtragem conhecido como deconvolução de Wiener-Levinson foi o utilizado no processamento aqui apresentado.

A deconvolução no SeisSpace é feita pelo módulo Surface Consistent Decon. Para isso, são geradas janelas de tempo no domínio do tiro em que são selecionadas

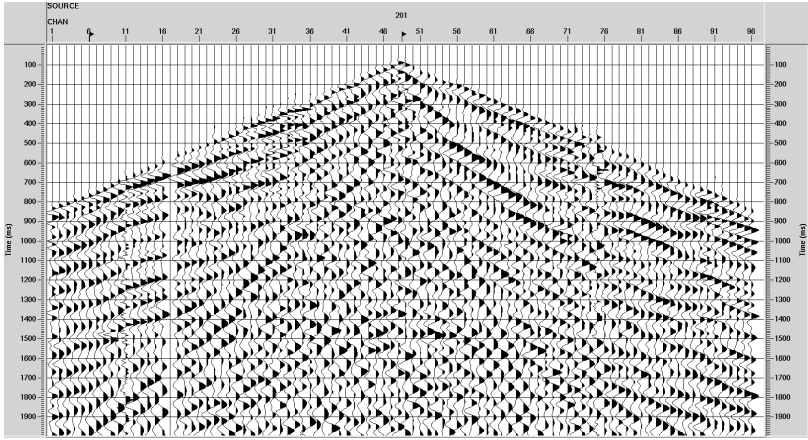

Figura 3: Tiro 201 após correção estática

as partes do sismograma que possuem reflexões mais evidentes para que seja feito o cálculo da auto-correlação dos traços e assim encontrar o filtro inverso, e então, aplica-se a deconvolução do pulso no dado. A Figura 3 mostra o resultado obtido após a deconvolução. Nele observa-se a maior resolução, principalmente no intervalo 500-900 ms.

\section{Filtragem}

Na sísmica de exploração, os ruídos que são observados nos sismogramas e que apresentam certa regularidade, tornando possível a sua predição traço a traço, são chamados de ruídos coerentes. Dentre esses, merece destaque o groundroll, de frequência por volta de $10 \mathrm{~Hz}$, que está presente nos dados sísmicos terrestres. $\mathrm{O}$ groundroll está associado às ondas superficiais do tipo Rayleigh associadas a faixa de 100 a 1000 m/s que ocorrem nas camadas de baixa velocidade, próximas à superfície (ZBV) Portanto, outra correção necessária é o limite de banda de frequência, onde são removidos dos traços os componentes de frequência menor ou maior do que o desejado, bem como o groundroll que pode ser visto claramente no lado esquerdo da Figura 4 por seu aspecto de um cone com grandes amplitudes e baixa frequência.

\section{Balanceamento espectral}

O filtro utilizado que apresentou melhores resultados, ou seja, atenuação do groundroll e realce das reflexões foi o balanceamento espectral e está apresentado na Figura 4 do lado direito. A aplicação do balanceamento espectral em dados contaminados por ruídos tais como, a onda aérea e o groundroll, cujos padrões são caracterizados por frequências anômalas, resulta na maioria das vezes, num aumento do sinal, uma vez que as componentes do espectro são levadas a um mesmo nível o que causa o decréscimo da energia total desses ruídos. (Souza, 2015) O balanceamento espectral consta das seguintes etapas:

1. Aplicação da transformada de Fourier para conversão dos dados para o domínio da frequência.

2. Separação desse dado em bandas de frequência com tamanho definido pelo processador selecionando ainda as freqüências de corte.

3. Aplicação da transformada de Fourier inversa para levar as bandas de frequência para o domínio do tempo. 
4. Aplicação da função ganho em cada banda que será favorecida ou atenuada segundo o entendimento do processador.

5. Concatenação das bandas restituindo o tamanho original do dado.

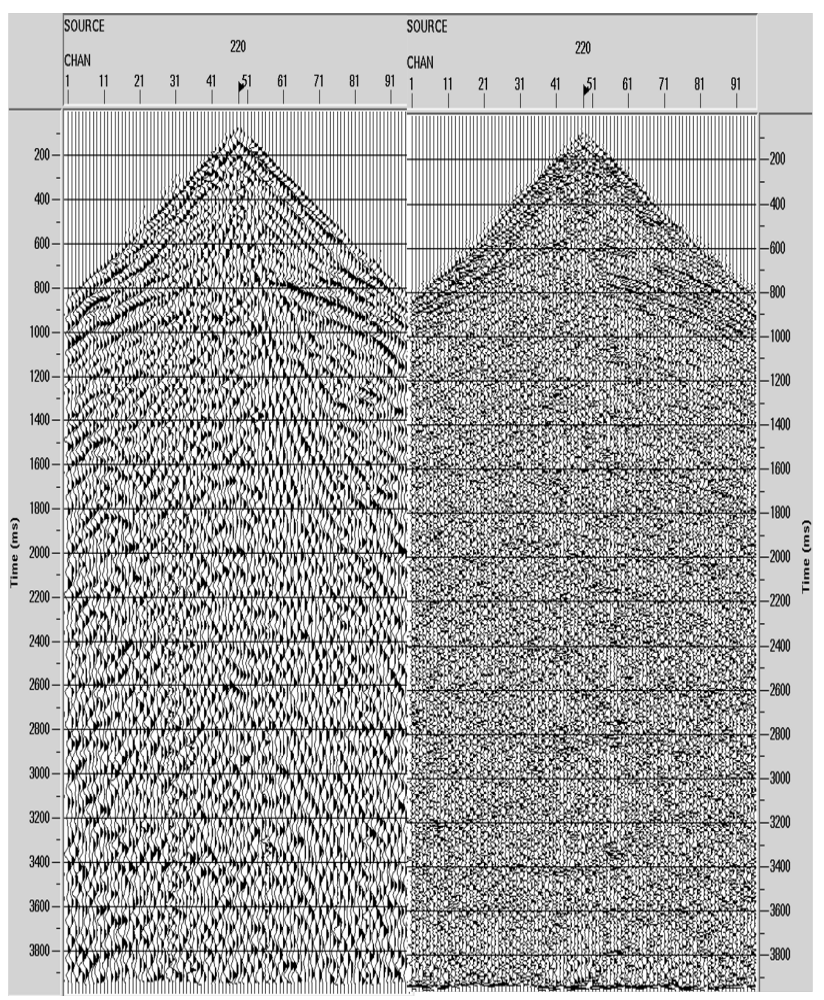

Figura 4: $A ̀$ esquerda, dado antes do balanceamento espectral; à direita, dado após o uso do filtro.

\section{Correção NMO}

A correção de Normal Moveout (NMO) objetiva o cálculo para cada sinal da resposta correspondente a uma onda de trajetória perpendicular ao refletor, ou seja, simular um afastamento nulo entre fonte e receptor. Isso pode ser realizado através de medições de propriedades acústicas em poços na área ou através da estimativa das velocidades das camadas através de análises gráficas. No processamento da linha 59-RL-44, fizemos a análise de velocidade com o auxílio de um semblance onde os pontos de maior coerência eram plotados possibilitando que os picks feitos de acordo com o display e conhecimentos teóricos sobre o modelo de camadas terrestres e a bacia em questão. O resultado dessa análise é um campo de velocidades como apresentado na Figura 6 de CMP versus tempo. Após tal estimativa, pode-se então fazer a correção dinâmica a fim de obter a seção zero-offset.

O caráter antes hiperbólico da reflexão de um refletor horizontal, agora passa a ser linear representando o tiro e estação em uma mesma coordenada.

\section{Empilhamento}

Após a correção NMO, os traços idealmente iluminam o mesmo ponto em subsuperfície, e os refletores estão

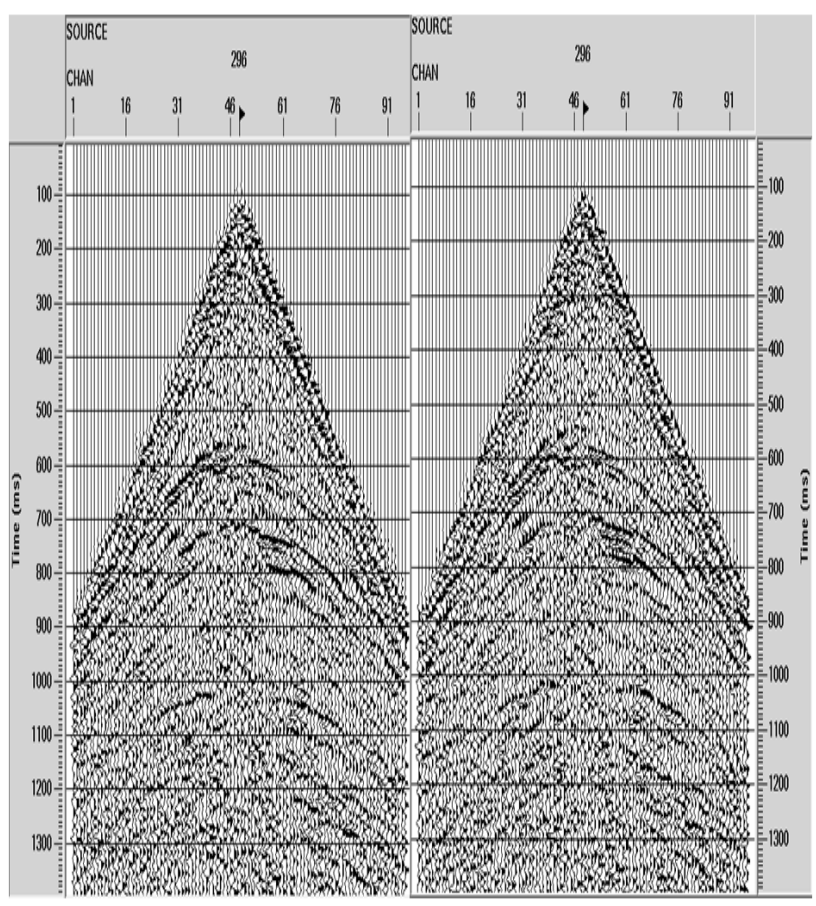

Figura 5: À esquerda, o dado antes da deconvolução e à direita, o dado após a deconvolução.

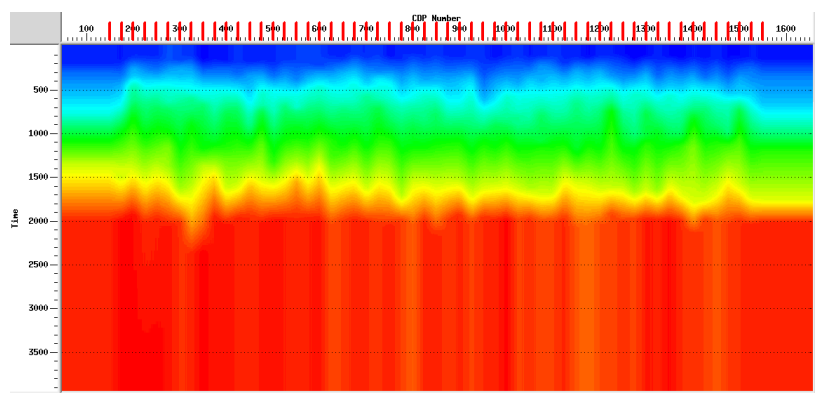

Figura 6: Campo de velocidade obtido

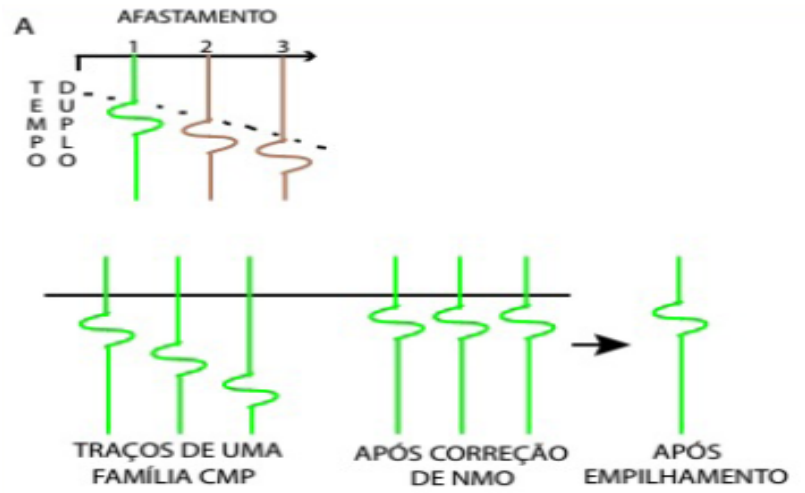

Figura 7: Empilhamento de traços sísmicos. Modificado de Ávila, 2010. 
alinhados, permitindo assim reforçar a coerência e atenuar o ruído não correlacionado, conforme representado na Figura 7. A seção empilhada é o resultado da soma aritmética das amplitudes dos traços de uma família CMP, justapostos lado a lado.

\section{Estática Residual}

Correções estáticas residuais são deslocamentos de tempo uniformes, assim como a correção estática préstack, são aplicados aos traços sísmicos pra compensar os tempos de atraso devido à ZBV. As anomalias distorcem a estratigrafia e estruturas aparentes na seção sísmica causando o desalinhamento e por isso, o objetivo dessa correção é obter o alinhamento de sinais primários em traços CMP preservando ao máximo o caráter de wavelet nos empilhamentos e assim, as feições reais em subsuperfície.

Para a estática residual apenas os tempos relativos entre traços são importantes e eles são obtidos a partir de correlações cruzadas entre os traços feitas a partir de janelas de tempo em que a razão sinal/ruído é grande definidas pelo processador. A função de correlação $\phi_{G H}$ entre traços é dada por:

$$
\phi_{G H}(t)=\frac{\sum_{t=t_{1}}^{t_{2}} G(t) H(t+\tau) d t}{\left[\sum_{t=t_{1}}^{t_{2}} G^{2}(t) d t \sum_{t=t_{1}}^{t_{2}} H^{2}(t) d t\right]^{1 / 2}}
$$

Em que $\mathrm{G}$ e $\mathrm{H}$ são os traços a serem correlacionados; $\tau$ é o tempo de atraso; $t_{1}$ e $t_{2}$ são os tempos inicial e final do dado. Para representar matematicamente a correção estática residual utiliza-se a seguinte função:

$$
t_{i, k, j}=S_{i}+R_{j}+G_{k h}+M_{k h} X_{i j}^{2}
$$

Onde $t_{i, k, j}$ é a estática residual observada no CMP em um horizonte $h ; \quad S_{i}$ e $R_{j}$ são as contribuições relativas às pequenas variações nas posições da fonte e receptores respectivamente; $G_{k h}$ é o fator de desempenho da subsuperfície na posição $k$ em superfície, sendo $k=(i+$ $j$ ) e $M_{k h} X_{i j}$, o fator de performance no offset $x=j-i$ que não é uma estática residual, mas sim um moveout residual devido a erros de velocidades e aproximação hiperbólica do NMO.

No software, a escolha do horizonte em que essa correlação será calculada é feita de forma interativa na própria seção empilhada por meio de picks de um traço piloto como mostrado na Figura 8. A redundância CMP é um fator importante visto que os ruídos aleatórios podem causar picos incorretos de correlações cruzadas. Por isso, faz-se necessário que a análise de velocidade já tenha sido feita e a correção NMO aplicada à família CMP garantindo melhor resolução e razão sinal-ruído. Note, na Figura 10 após aplicação da correção estática, a melhoria no alinhamento e continuidade dos refletores, comparando-a com a Figura 9, sem correção estática.

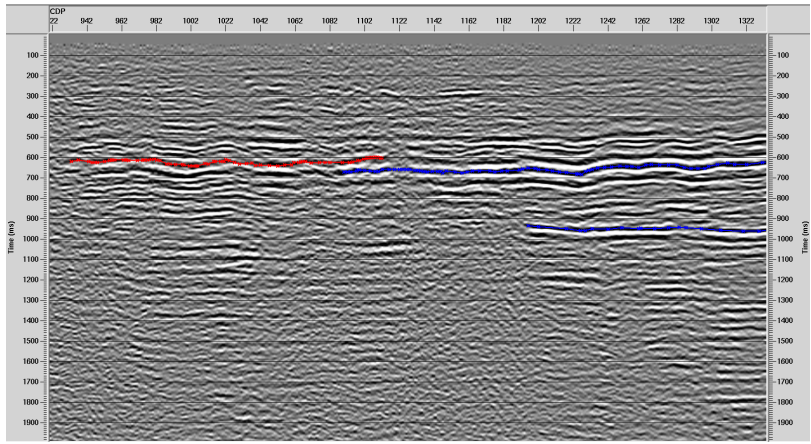

Figura 8: Picks marcando o horizonte para estática residual.

\section{Discussão e conclusão}

A seção empilhada final (Figura 11) resultou em uma imagem relativamente boa com os refletores bem. $O$ uso do balanceamento espectral atrelado a deconvolução spike com consistência superficial foi determinante para a melhoria da razão sinal/ruído conferindo ao dado maior resolução e definição das camadas. Pelo fato dos refletores serem planos e não haver estruturas que geram difrações, a etapa da migração não foi necessária. Entretanto, a estática residual se revelou uma ferramenta de extrema importância considerando o caráter plano dos refletores e a limitação da estática pré-stack.

\section{Agradecimentos}

Os autores agradecem ao CNPq e PETROBRAS pelo apoio ao projeto INCT-GP/CNPQ/MCTI, ao LAGEP/CPGG pelo apoio à realização desse trabalho e à Landmark por ceder o software SEISSPACE utilizado. E por fim, à ANP e a BP por ceder os dados aqui apresentados.

\section{Referências}

Ávila, R.M. 2010. Reprocessamento de Dado Sísmico 2D da Bacia do Parnaíba. Dissertação de Mestrado. COPPE, Universidade Federal do Rio de Janeiro, Rio de Janeiro, Brasil. 66 p.

Bizzi, L. A., Schobbenhaus, C., Vidotti, R. M., e Gonçalves, J. H. (eds.). 2003, Bacias Sedimentares Paleozóicas e Meso-Cenozóicas Interiores CPRM, Brasília, Brasil. 68p.

Silva, M.G. 2004. Processamento de Dados Sísmicos da Bacia do Tacutu. Dissertação de Mestrado. Universidade Federal da Bahia, Salvador, Brasil. 126 p.

Souza, W. E. e Botelho, M. A. B., 2015. Processamento CMP de Dados Sísmicos Levantados no Norte da Bacia do São Francisco: 14th International Congress of the Brazilian Geophysical Society, Rio de Janeiro, Brasil. 


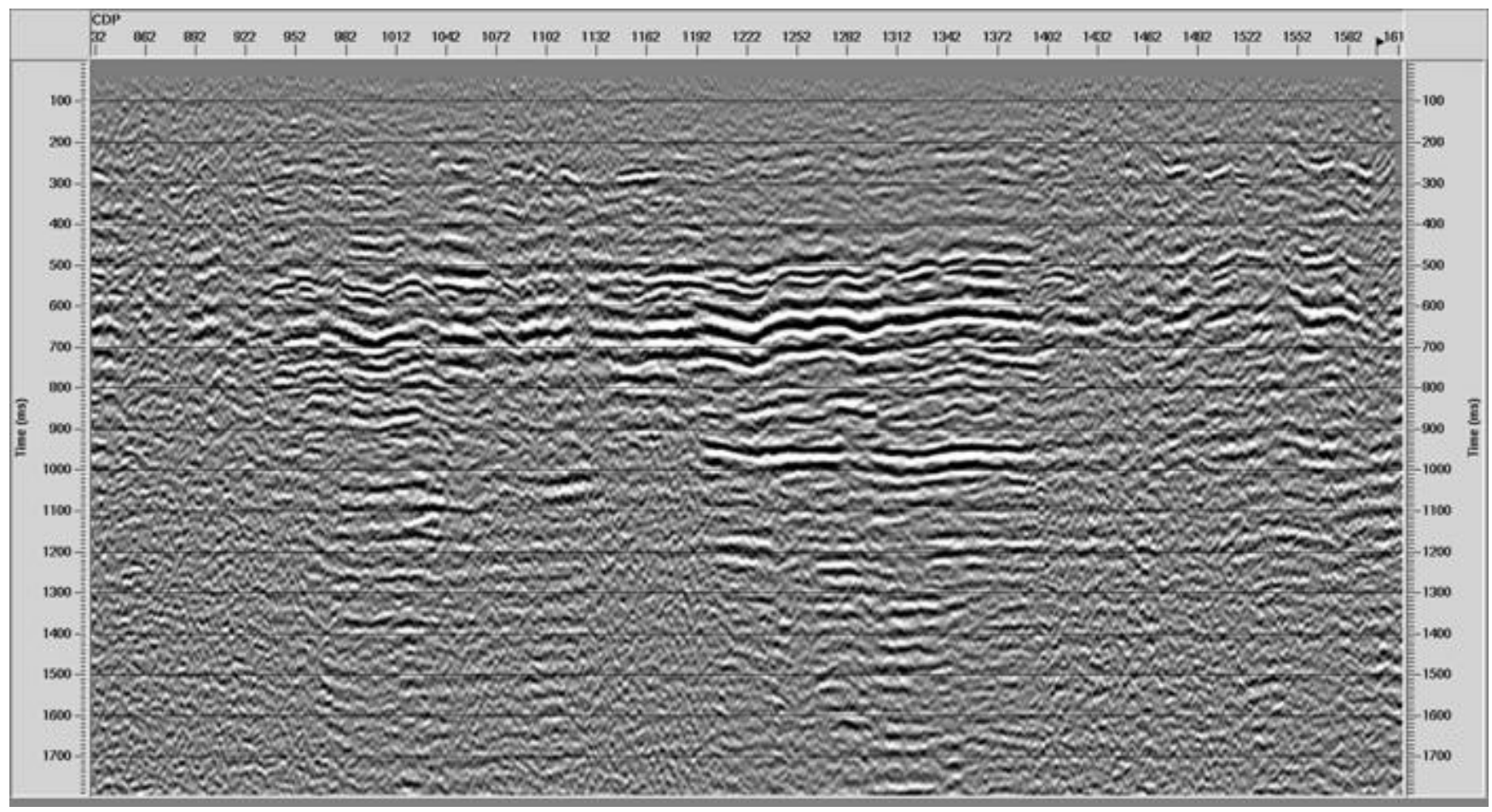

Figura 9: Seção sísmica empilhada sem estática residual.

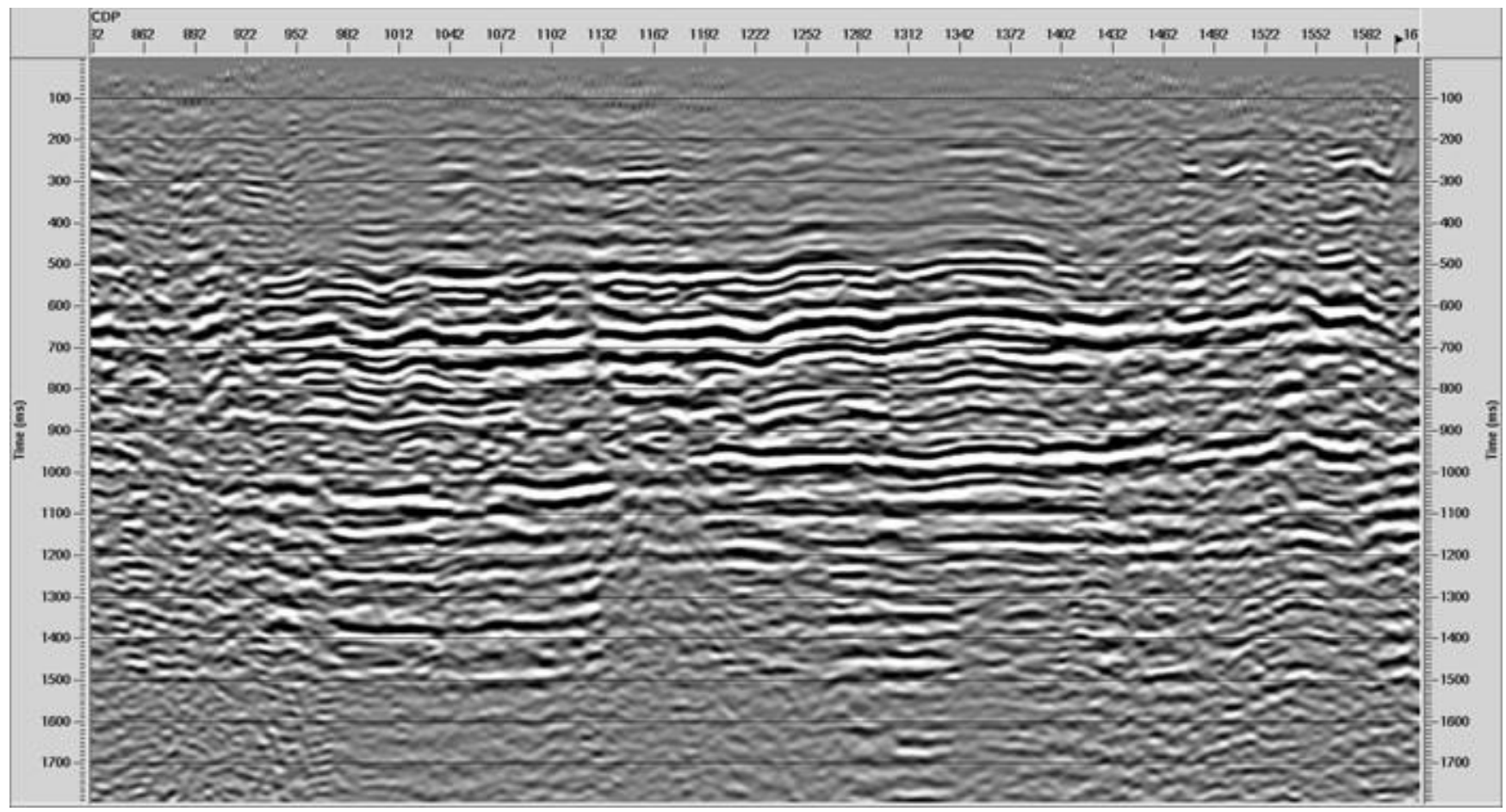

Figura 10: Seção sísmica empilhada com estática residual. 


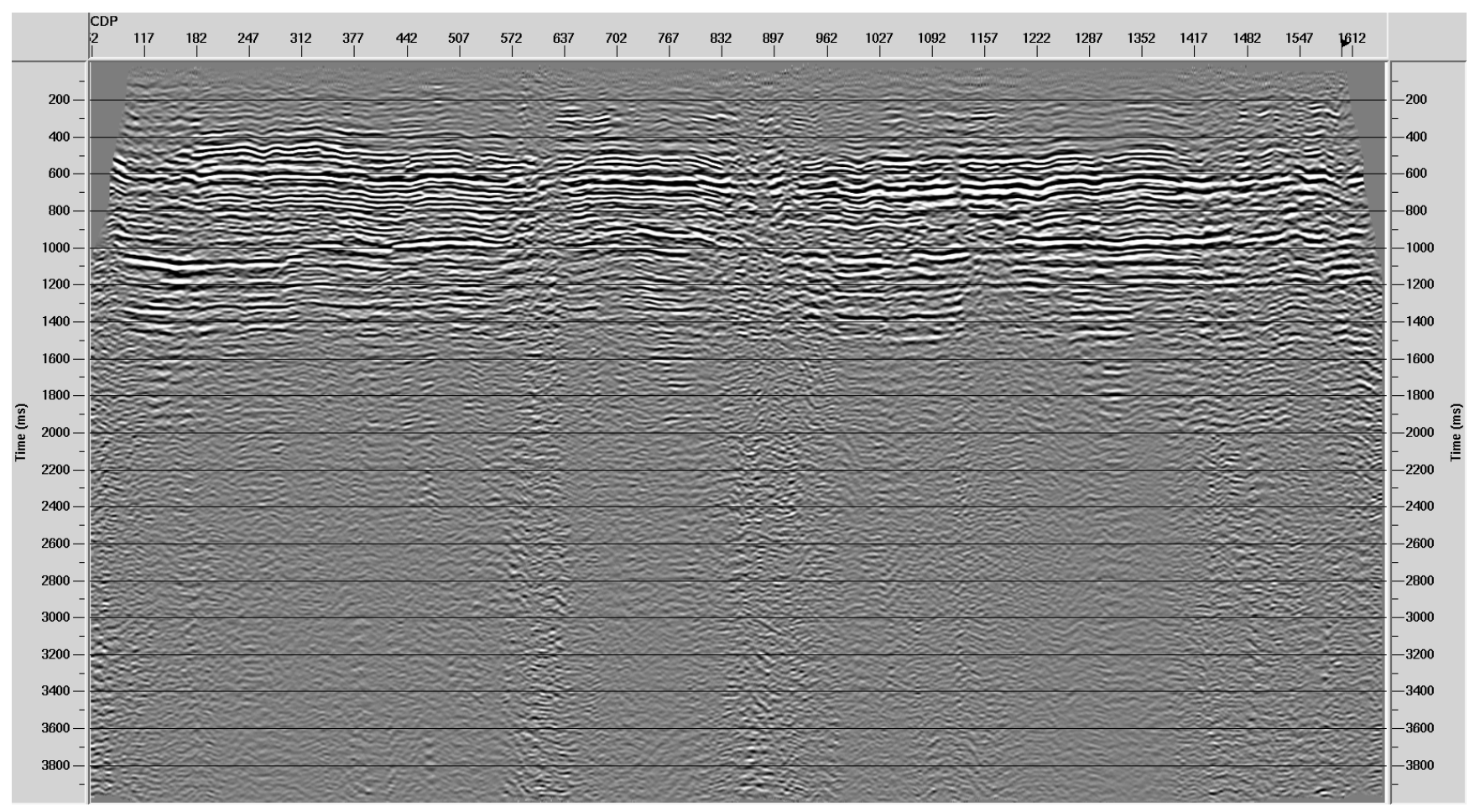

Figura 11: Seção sísmica empilhada final 